\title{
Substance use and associated factors and associated factors among preparatory school students in Nekemte town western Ethiopia; school based a cross- sectional study
}

Markos Desalegn Beyene ( $\square$ markosdesalegn@gmail.com )

Jigjiga University

Robsan Gudeta Getachew

Wollega University

Workineh Diriba Gemechu

Jigjiga University

Research

Keywords: substance use, students, associated factors

Posted Date: January 1st, 2020

DOl: https://doi.org/10.21203/rs.2.19847/v1

License: (c) (1) This work is licensed under a Creative Commons Attribution 4.0 International License.

Read Full License 


\section{Abstract}

Background: Millions of people throughout the world are using substances such as alcohol, nicotine, cocaine, methamphetamine, morphine, marijuana, heroin and many others. Substance use by people in all parts of the world, particularly adolescents, has long been of scientific, political and public concern. Objective: -the main aim of this study was to prevalence of substance use \& associated factors among Nekemte preparatory school students in 2019. Methodology:-. School based cross-sectional study was conducted among students at Nekemte preparatory school from March 20-30, 2018. Multistage stratified sampling method was employed to select 372 study participants. Collected data was cleaned and entered in to Epi info version 3.5.3 and transported to SPSS (statistical package for social sciences) version 20 for analysis. Descriptive statistics and logistic regression was done to indentify factors associated with substance use in the study area. Result: The overall prevalence of current substance use was (19.1\%). Being male students [AOR, 95\% Cl; 4.64(2.18, 9.75)], ever encountered pressure from friends to use substances [AOR, $95 \% \mathrm{Cl} ; 2.61(1.03,6.63)]$, having substance user parents [AOR, $95 \% \mathrm{Cl} ; 6.4(2.87$, $14.30)]$ and having many substance user friends $[A O R, 95 \% \mathrm{Cl} ; 6.2(2.82,13.75)]$ were significantly associated with substance use among students in the study area. Conclusion \& Recommendation: The current prevalence of substance use among preparatory school students of this study area was low. The most commonly used substances were alcohol, khat and tobacco. Being male students, pear pressure, living with parents use substance \& friends were found to affect substance use among Nekemte preparatory school students. Awareness creation sessions; Information, Education \&Communication intervention should be intensified to further reduce Substance use among students.

\section{Background}

The World Health Organization (WHO) estimates that about 30\% of the adult male global population smokes. National smoking prevalence among men in sub-Sahara Africa varies from $20 \%$ to $60 \%$. Smoking is estimated to cause about $71 \%$ of lung cancer, $42 \%$ of chronic respiratory disease, $10 \%$ of cardiovascular diseases and stroke(1).

In 2012 , about 3.3 million deaths or $5.9 \%$ of all global deaths were attributable to alcohol consumption, 139 million DALYs (disability adjusted life years) or $5.1 \%$ of the global burden of disease and injury were attributable to alcohol consumption(2).

Burden of impairment attributable to alcohol and tobacco are 5.4 and3.7\%; cause for death of 2.5 and 6 million people each year respectively. chat and alcohol use is linked to unprotected sex, putting young people at risk of unwanted pregnancy, abortion and HIV/ ADIS infection (3).

substance use is common among adolescent or young people the world wide and almost all secondary school student are the domain of this age (4). Because, students or this age group population has low perceived risk for substance use, family and friends who use substance, community laws and norms favorable to drug use and poverty(5). Not only this abut also multiple interacting factors influence 
substance use like :availability, social acceptability, and peer pressures, particular actions of the substance, personality and individual biology(6).Similarly, age, sex, unemployment, low education levels, poor health, low income families, lack of family support and conflict in the family can be factors lead individual to use substance (7).

Despite this substance abuse is being taken as assign of modernity or civilization among secondary school or young population. This period is the beginning of time when young people start influenced by peers and get independent from family control. Therefore the aim this study is to determine prevalence of substance abuse and contributing factors among preparatory school students in Nekemte town.

\section{Methods}

\section{Study design and setting}

School based crossed sectional study design was conducted among Nekemte preparatory school students from March 20-22, 2018. Nekemte town is located at $328 \mathrm{~km}$ to west of Addis Ababa. The town has 11 government primary full cycle schools, 26 Private primary schools, as well as 5 Governmental \& 5 Private secondary schools where as 3 Governmental \& 3 Private Preparatory schools. Nekemte preparatory school was randomly selected and the school has 42 sections; 25 Sections of them are grade $11^{\text {th }} \& 17$ Sections are grade $12^{\text {th }}$. Total of 3491 Students were attending the class during the study period, 2295 grade $11^{\text {th }} \& 1196$ grade $12^{\text {th }}$ were considered as study population. Sample size was calculated using single population proportion, using proportion 14.10, 95\% confidence interval, 5\% marginal error, design effect of 2 and $10 \%$ non response rate. Then the final sample size was determined to be 372 .

\section{Sampling procedure}

Multistage stratified sampling technique was employed to select across different sections. First the students were stratified based on their grade (grade $11^{\text {th }}$ and grade $12^{\text {th }}$ ). The proportion to size sample was assigned to both grades $\left(11^{\text {th }}\right.$ and $\left.12^{\text {th }}\right)$. Then $20 \%$ of the sections were considered from each grade and 8 sections and 4 sections from $11^{\text {th }}$ and $12^{\text {th }}$ grade were selected. Again sample was assigned to each selected section of each grade $\left(11^{\text {th }}\right.$ and $\left.12^{\text {th }}\right)$ and systematic sampling method was employed using different sampling fraction to select individual respondents.

\section{Data collection and tools}

Instrument/tool: Data was collected using self- administered structured questionnaire was used to collect information on socio demographic data and other important data related to objectives of the study. The tool was adopted from The European School Survey Project on Alcohol and Other Drugs (8) and modified based on the scope this study which was prepared first in English and translated to Afaan Oromo and translated back to English by other individual to check consistency of the tool. Data collection 
facilitators were experienced individuals but not instructors in the same school and training was given by the principal investigators specially how to create conducive environment for the respondents during data collection, and how to give clarity, if there is any inconvenience. Following an orientation, questionnaire was distributed for selected student based on sampling fraction and filled in private

\section{Data quality management}

Structured questionnaire was adopted and modified according to the variables included in the study and pre-test was conducted to see, if there is ambiguous question and appropriate corrections were given before the actual data collection. Data collectors were trained and strict supervision were there during data collection. Data was double entered to check the consistency

Data processing and analysis

Data were coded, entered into Epi info version 3.5.3 and exported to SPSS version 20.0 for analysis. Descriptive statistics were computed to determine the frequency and percentages. Binary logistic regression was conducted and COR, with $95 \% \mathrm{Cl}$ was estimated to select the candidate variables for the final model. Then, variables with a p-value of $<0.3$ were candidate variable for multivariable logistic regression.. Hosmer-Lemeshow goodness-of-fit with stepwise (backward elimination) logistic regression was used to test for model fitness. AOR with $95 \% \mathrm{Cl}$ was estimated to assess the presence of association at multivariable logistic regression. Finally, variables with a $p$-value of $<0.05$ were considered as statistically significant predictors of the outcome variable.

\section{Operational definition}

Substance: For this study it was defined as alcohol, khat, cigarettes and illicit drugs to alter their mood or behavior.

Substance abuse: For this study it was defined as the abuse of alcohol, khat, cigarettes and illicit substances by students.

Current use: having consumed or used substance at least once in the past 30 days.

Ever use: an individual is considered as ever use if he/she consume at least once in his/her lifetime.

\section{Ethical clearance}

Ethical clearance was obtained from the Research and Ethics Committee of Wollega University. An official letter was written to each hospital to get official permission. Participants were informed that privacy and confidentiality will be maintained on the information sheet and written consent form. Written consent was taken from study participants.

\section{Results}


A total of 372 respondents participated in this study and all of them filled the questionnaire completely with response rate of $100 \%$. Majorities (57\%) of participants were male in sex, $(72.3 \%)$ were protestant in religion and (85.5\%) were Oromo in ethnicity. The most common source income for the participants were their parents (table 1 )

Substance use and reasons for substance use among Nekemte preparatory students

Over all prevalence of current substance use was (19.1) where 50(13.4\%) were alcohol users, 35(9.4\%) khat chewer and 29(7.8\%) were cigarette smokers currently. Substance users responded that they use substances commonly to expend time $31(8.3 \%)$ and for entertainment $26(7 \%)$. One hundred eleven $111(29.8 \%)$ of the respondents had ever used one of the substance or any at least once in their life and alcohol was the most ever used substance $56(15.0 \%)$. peer pressure 55(14.8\%), academic performance $28(7.5 \%)$, family problem and challenges of life $16(4.3 \%)$ and availability of substance $12(3.2 \%)$ were the basic motivational factors for the student to use substance at least once in their life. Only few $12(3.2 \%), 8(2.2 \%)$ and $7(1.8 \%)$ of $f$ respondents mentioned that they had encountered unprotected sex, injury/accident and physical flight after substance use (table 2, figure 1)

\section{Factors associated with substance use among Nekemte preparatory school students}

Result of Multivariate logistic regression showed; sex of participants, grade level, students having parents using substance, having friends using substance and presence of peer pressure were found to statistically significant variable to affect substance use among Nekemte preparatory school.

Respondents male sex were 4.6 more likely to use substance (AOR $[95 \% \mathrm{Cl}]=4.6[2.18-9.75]$ ) compared to their female sex. Students of grade 12th was 2.4 more likely to use substance compared to those grade $11^{\text {th }}$ students of same school (AOR [95\% Cl] $\left.=2.4[1.14-4.94]\right)$. Respondents having parents and friends using substance were about 6 times more likely to use substance compared to their counterparts (AOR $[95 \% \mathrm{Cl}]=6.4[2.9-14.30])$ and $(\mathrm{AOR}[95 \% \mathrm{Cl}]=6.23[2.82-13.78])$ respectively. On the other hand students who have encountered peer pressure were about 3 times more likely to use substance $(\mathrm{AOR}[95 \% \mathrm{Cl}]$ $=2.61[1.02-6.63])$ (table 2).

\section{Discussion}

Prevalence of substance use among students in this study area was $19.1 \%$. This finding was lower than study done among high school adolescents in Woreta Town, Northwest Ethiopia of which current $47.9 \%$ (5). The difference might be due to difference in study period when information, education and legislation is being intensified to reduce substance use. Reasons mentioned by respondent to use substance were: to socialize $18(36 \%)$ and for entertainment $18(51.4 \%)$ whereas the most basic motivation for substance use in this area was peer pressure 55(49.5\%). This finding was in line with Study done in Debere Birhan university students and Haramaya University students where the reasons for substance use were enjoyment, to stay awake peer pressure, to socialize and to improve academic performance $(2,9,10)$ 
In this study area, the most commonly used substance were alcohol 50 (13.4\%), khat 35(9.4\%) \& tobacco29 (7.8\%). This is also lower than finding in Dire Dawa secondary school and Ginnir town preparatory school , Bale zone $(11,12)$. This difference may be due to difference in stud area where there is availability of chat and otter substance. On the other hand most of the populations in these two areas (Dire Dawa \& Ginnir town, Bale Zone) are Muslim in religion and some research reveal that being Muslim is strongly associated with chewing chat and other substance (13).

The result of multivariate logistic regression revealed that, there were factors associated with substance use among Nekemte preparatory school student. Being male sex was strongly associated with substance use in this study area which is in line with study conducted in Addis Ababa University and Haramaya university health and medical students and jigjiga university students $(9,10,14$,$) . Other finding$ from systemic review of alcohol consumption in Ethiopia support this finding that, the prevalence of hazardous alcohol consumption was remarkably higher in men than in women (15). Level of education attained or grade of students were found to influence substance use among our respondents where students of $12^{\text {th }}$ grade were more likely to use substance than their counterparts. In Jigjiga university the odds of drinking alcohol was higher among senior students; those at 3rd year those at 4th year; compared with their junior 2nd year students $(9,14)$

In our study having many friends using substance were found to affect substance use among preparatory students. In Addis Ababa substance use was high among those students whose friends were drinking alcohol (13) also in Debra Berhan University the study revealed, having substance user families and friends were found to be variables significantly associated with students' substance use behaviors(2).

Having family or parents using substance was another predictor of substance use among students of our study area which is similar to study conducted in Debra Berhan University students, Haramaya University health and medical science students where students from substance user families were more likely to use substance and in Debra Markos poly technique college history of family drug use was highly associated with students substance use $(7,11,12$,$) . In this study peer pressure was strongly associated with$ substance use among students in our study area. In Debra Markos poly technique college students who had experienced peer pressure was more likely to use substance than their counterparts (6).

The study has different limitation First; the study used a descriptive single cross-sectional design that cannot establish trends and causality between substance use and risk factors. Second, the data was collected using self administered questionnaire which may be subjected to recall bias and under-reporting of substance use due to social desirability bias. Finally, the types substance reported in this study were cigarette, alcohol and kchat only. Despite the limitations, our finding has substance finding which encourage the family, community, teachers and other stakeholders to give attention for substance use among students.

\section{Conclusion and recommendation}


The prevalence of substance use in this study was low. The most commonly used substances were alcohol, khat and tobacco where the main reasons mentioned by respondents to use substance were: to socialize, for entertainment whereas the most basic motivation for substance use in this area was peer pressure. Being male students, pear pressure, living with parents use substance \& friends were found to affect substance use among Nekemte preparatory school students. Awareness creation sessions; Information, Education \&Communication intervention should be intensified to further reduce Substance use among students. Further research should be conducted to explore for other factors associated with substance use not only for the three substance mentioned but also other substances in other setting other than preparatory school.

\section{Declarations}

\section{Ethical consideration}

Ethical clearance was obtained from Wollega University, School of Public Health Ethical Review committee. Permission for conducting the study was secured from the Nekemte Town Health bureau. Written consent was obtained from all the study participants after they had briefed about the objectives and the aim of the research. Confidentiality of the information gathered was assured to the interviewee.

\section{Acknowledgment}

The authors like to acknowledge Wollega University, Institute of Health Sciences and their library for giving us support. In addition, we would like to thank the study participants, data collectors, and supervisors.

\section{Competing interest}

The authors declare that they have no conflicts of interest regarding the publication of the paper.

Consent for publication: Not applicable

Availability of the data and material: The corresponding author can make the required data and material whenever needed

Funding: Not applicable

\section{Authors' contribution}

Markos Desalegn is the principal investigator who initiated and involved in the proposal development, analysis of the data, interpretation of the data, report writing, and manuscript preparation. Robsan Gudeta and Workineh Diriba involved in the preparation of the manuscript and reviewing the paper

\section{Abbreviations}


AIDS: Acquired Immune Deficiency Syndrome

ATS: Amphetamine-Type Stimulant

Cl: Confidence Interval

DALYs: Disability-Adjusted Life Years

EFMHACA: Ethiopia Food Medicine and Health Care Administration and Control Authority

FCTC: Framework Convention on Tobacco Control

Go: Governmental Organizations

HIV: Human Immune Virus

Ngo: Non- Governmental Organizations

NRT: Nicotine Replacement Therapy

OR: Odds Ratio

SD: standard deviation

SPSS: Statistical Package for Social Sciences

STI: Sexually Transmitted Infections

US: United State

WHO: World Health Organization

\section{References}

1. Walelgne W, Yadeta D, Feleke Y. Ethiopian National Guideline on Major NCDs 2016 Guidelines Clinical and Programmatic Management of Major Non Communicable Diseases. 2016;(June).

2. Gebremariam et al. Substance use and associated factors among Debre Berhan University students, Central Ethiopia Substance Abuse Treatment, Prevention, and Policy (2018) 13:13

3. Rezahosseini, Omid et al. "Drug Abuse among University Students of Rafsanjan, Iran." Iranian journal of psychiatry and behavioral sciencesvol. 8,2 (2014): 81-5.

4. Deribachew Hailemariam and Lidiya Fasil, 2017."Prevalence and associated factors of substance abuse among under graduate regular students", International Journal of Development Research, 7, (11), 16995-17000.). 
5. Birhanu AM, Bisetegn TA, Woldeyohannes SM. High prevalence of substance use and associated factors among high school adolescents in Woreta Town , Northwest Ethiopia: multi-domain factor analysis. 2014;1-11.

6. Tesfahun Aklog, Gebeyaw Tiruneh \& Girmay Tsegay. Substance Abuse and Associated Factors among Students of Debre Markos Poly Technique College in Debre Markos Town, East Gojjam Zone, Amhara Regional State, Ethiopia, 2013: Global Journal of Medical research Pharma, Drug Discovery, Toxicology and Medicine, Volume 13 Issue 4 Version 1.0.Online ISSN: 2249-4618 \& Print ISSN : 09755888

7. Bagheri S, Rezaie F, Fallahi A, Shahsavari S, Pashaei T. The prevalence and the risk factors associated with tranquilizer abuse in the population with the age of over 18 years in Iran. 2018;6(1):29-35.

8. European School Survey Project on Alcohol and Other Drugs (ESPAD). Compendium of basic information on child or family-focused cross-national surveys: available at: www.espad.org .accessed on March June 2018.

9. Gezahegn Tesfaye et al. Substance Use and Associated Factors among University Students in Ethiopia: A Cross-Sectional Study: Journal of Addiction Volume 2014, Article ID 969837, 8 pages http://dx.doi.org/10.1155/2014/969837

10. Alebachew et al. Prevalence, associated factors and consequences of substance use among health and medical science students of Haramaya University, eastern Ethiopia, 2018: a cross-sectional study BMC Psychiatry (2019) 19:343

11. Dida, Nagasa et al. "Substance use and associated factors among preparatory school students in Bale Zone, Oromia Regional State, Southeast Ethiopia." Harm reduction journalvol. 11 21. 9 Aug. 2014, doi: 10.1186/1477-7517-11-21

12. Town G, Zone B. Assessment of substance use and associated factors among high school and preparatory school students of. 2014;2(6):414-9.

13. Deressa and Azazh: Substance use and its predictors among undergraduate medical students of Addis Ababa University in Ethiopia. BMC Public Health 2011 11:660.

14. Gamachu Fufa et al.: The Nexus between Khat and Other Drug use among Undergraduate Students of Jigjiga University in Ethiopia; Contributing Factors and Prevalence Rates. Public Health Research 2017, 7(2): 49-54

15. Ayano et al. The epidemiology of alcohol consumption in Ethiopia: a systematic review and meta analysis. Substance Abuse Treatment, Prevention, and Policy (2019) 14:26

\section{Tables}

Table1: socio demographic characteristics of respondents in Nekemte preparatory school, Nekemte, March 2018. 


\begin{tabular}{|c|c|c|c|}
\hline s.no & Socio demography & Frequency & Percentage \\
\hline \multirow[t]{3}{*}{1} & \multicolumn{3}{|l|}{ Sex } \\
\hline & Male & 212 & 57 \\
\hline & Female & 160 & 43 \\
\hline \multirow[t]{4}{*}{2} & \multicolumn{3}{|l|}{ Age in years } \\
\hline & $15-20$ & 256 & 68.8 \\
\hline & $21-25$ & 112 & 30.1 \\
\hline & $26-30$ & 4 & 1.1 \\
\hline \multirow[t]{5}{*}{3} & \multicolumn{3}{|l|}{ Religion } \\
\hline & Protestant & 269 & 72.3 \\
\hline & Orthodox & 64 & 17.2 \\
\hline & Muslim & 17 & 4.6 \\
\hline & Others & 22 & 5.9 \\
\hline & \multicolumn{3}{|c|}{ Level of education attained Grade } \\
\hline & $12^{\text {th }}$ & 128 & 34.4 \\
\hline & $11^{\text {th }}$ & 244 & 65.6 \\
\hline & \multicolumn{3}{|c|}{ Parents history of substance use } \\
\hline & Yes & 60 & 16.1 \\
\hline & No & 312 & 83.9 \\
\hline
\end{tabular}

Table 2: number of respondents by substance use among study participants in Nekemte preparatory school, Nekemte, March 2018 


\begin{tabular}{|c|c|c|c|}
\hline s.no. & Substance in use & Frequency & Percentage \\
\hline & \multicolumn{3}{|l|}{ Chewing Khat } \\
\hline & Yes & 35 & 9.4 \\
\hline & No & 337 & 90.6 \\
\hline \multirow[t]{3}{*}{2} & \multicolumn{3}{|l|}{ Drinking Alcohol } \\
\hline & Yes & 50 & 13.4 \\
\hline & No & 322 & 86.6 \\
\hline \multirow[t]{3}{*}{3} & \multicolumn{3}{|l|}{ Smoke Cigarette } \\
\hline & Yes & 29 & 7.8 \\
\hline & No & 343 & 92.2 \\
\hline
\end{tabular}

Table 3: Multivariate and Bivariate analysis of selected variables affecting substance use among Nekemte preparatory school students, Nekemte, March 2018. 


\begin{tabular}{|c|c|c|c|c|c|}
\hline \multirow[t]{2}{*}{ Variables } & \multicolumn{5}{|c|}{ Substance use } \\
\hline & Total & Yes & No & COR, (95 CI) & $\mathrm{AOR},(95 \mathrm{CI})$ \\
\hline \multicolumn{6}{|l|}{ Sex } \\
\hline Male & 212 & $55(25.9)$ & $157(74.1)$ & $3.23,(1.77-5.89)$ & $4.64,(2.18-975)$ \\
\hline Female & 160 & $16(10)$ & 144(90) & 1.0 (ref) & \\
\hline \multicolumn{6}{|c|}{ Level of education attained(grade level) } \\
\hline $12^{\text {th }}$ grade & 128 & $89(69.5)$ & $39(30.5)$ & $2.80,(1.66-4.74)$ & $2.37,(1.14-4.94)$ \\
\hline $11^{\text {th }}$ grade & 244 & $212(86.9)$ & $321(13.1)$ & 1.0 (ref) & \\
\hline \multicolumn{6}{|c|}{ Having friends who use substance } \\
\hline Yes & 86 & $44(51.2)$ & $42(48.8)$ & $9.65,(5.43-17.16)$ & $6.24,(2.82-13.78)$ \\
\hline No & 286 & $27(9.4)$ & $259(90.6)$ & 1.0 (ref) & \\
\hline \multicolumn{6}{|c|}{ Living with family who use substance } \\
\hline Yes & 60 & $27(45)$ & $33(55)$ & $4.86,(2.67-8.88)$ & $6.4,(2.87-14.30)$ \\
\hline No & 312 & $45(14.4)$ & $267(85.6)$ & 1.0 (ref) & \\
\hline
\end{tabular}

\section{Figures}

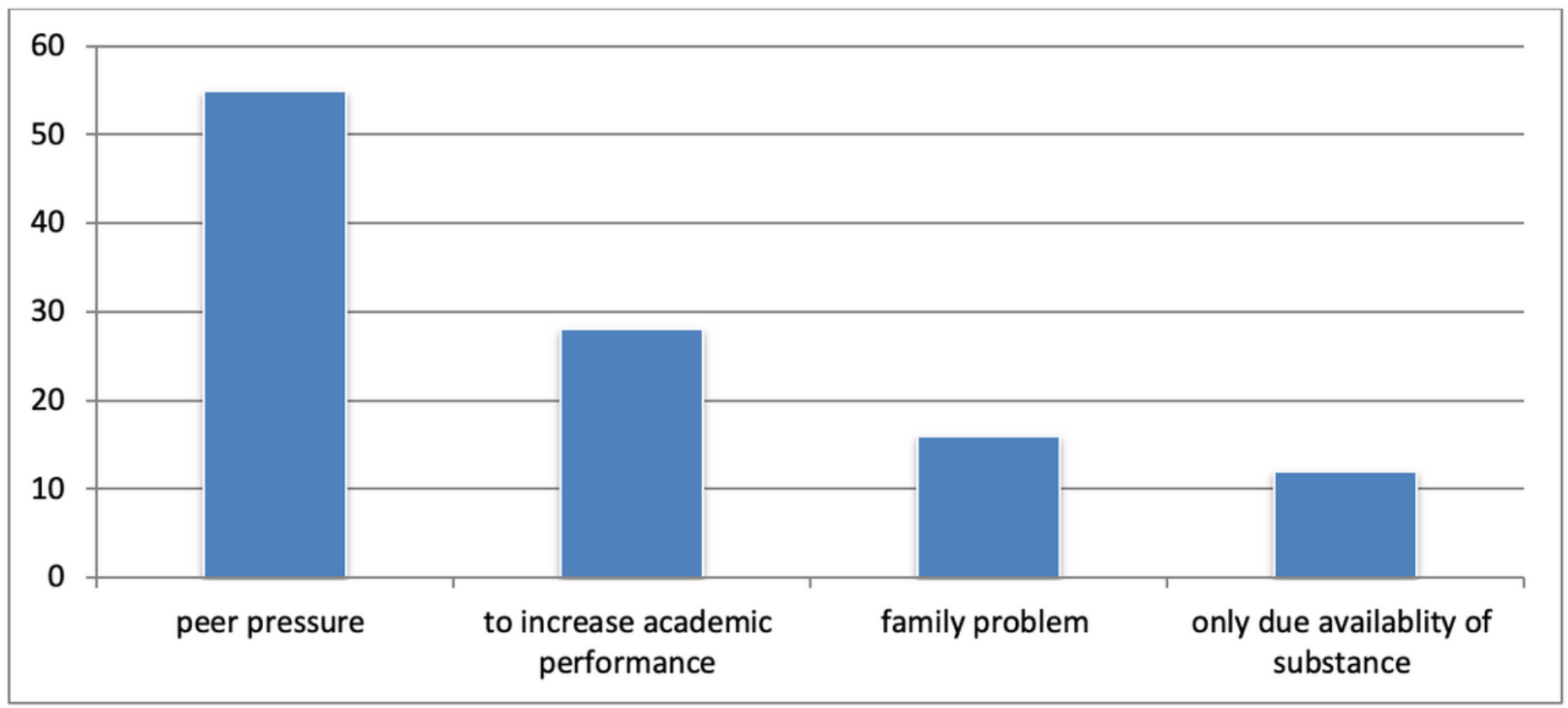




\section{Figure 1}

Reason for ever use of substance among Nekemte preparatory school students, march, 2018 